\title{
ACTI-DIONE AND NATURAL BARK EXTRACTS IN THE CONTROL OF HYPOXYLON CANKER OF POPLAR ${ }^{1}$
}

\author{
BY JOHN E. BIER ${ }^{2}$
}

\begin{abstract}
Canker attack by Hypoxylon pruinatum (Klotzsch) Cke. did not occur when inoculations were made on dormant cuttings of Populus trichocarpa Torrey and Gray that had been dipped in a $1 / 10,000$ aqueous solution of Acti-dione concentrate, and provided with a continuous water supply. However, the antibiotic was not successful in disease control when water was withheld temporarily from the dipped and inoculated cuttings. Canker spread was arrested when water was supplied to these partially dried cuttings, although it was evident that the antibiotic had caused injury to the developing shoots and roots. The results demonstrated that successful control by Acti-dione was dependent on the maintenance of normal water relations in the experimental trees.

The Acti-dione tests are discussed in relation to the excellent control obtained in earlier experiments by the application of extracts of bark saprophytes to susceptible host material.
\end{abstract}

\section{INTRODUCTION}

The results of recent studies (3) have shown that water extracts of the saprophytes (fungi, bacteria and yeasts) that occurred on and within the healthy bark and wood of poplars, willow, Douglas fir and Western hemlock were highly effective in inhibiting the cultural growth of Hypoxylon pruinatum (Klotzsch) Cke. Furthermore, infection and disease spread did not occur when extract-dipped cuttings of a susceptible host were inoculated and provided with a continuous supply of water. The effectiveness of the saprophytes in canker control was lost when the bark moisture level was reduced by withholding water from the inoculated trees. It appeared that when the bark moisture level of Populus trichocarpa Torrey and Gray was maintained at or above the established threshold level for infection (2), the activities of the saprophytes resulted in the production and circulation of natural antibiotics that prevented canker attack.

The results summarized indicated that it would be of interest to conduct similar experimentation on biological control using a described and tested antibiotic as Acti-dione (4).

\section{Methods}

The methods of inoculation, incubation, surface sterilization of cuttings, preparation of extracts and antagonism tests, and the determination of bark moisture (turgor) level have been outlined previously (3). One-yearold shoots of dormant $P$. trichocarpa were used as host material.

\footnotetext{
${ }^{1}$ Contribution from the Faculty of Forestry (Research Note No. 38), and the Department of Biology and Botany of the University of British Columbia, Vancouver 8, B.C. Financia support for these studies was granted by the National Research Council of Canada, and MacMillan, Bloedel and Powell River Ltd.

'Biography in For. Chron, 31, 324, 1955. Appointed Professor of Forest Pathology, University of British Columbia in July, 1956.
} 


\section{RESULTS}

The results of cultural studies demonstrated that one part of Actidione concentrate in 10,000 parts of water was effective in inhibiting the mycelial growth of Hypoxylon (Fig. 1). Aqueous solutions of the antibiotic at this concentration were used in the control tests.

The Inoculation of Acti-dione Dipped and Surface Sterilized Cuttings of Black Cottonwood Provided With a Continuous Water Supply

Disease development did not occur when the inoculations were made on natural and surface sterilized cuttings that had been dipped in the Acti-dione solution. Canker attack did occur on the surface sterilized controls (Fig. 2). The results of previous studies (3) have demonstrated that surface sterilized cuttings were susceptible to the disease at very high levels of bark and wood moisture. In these experiments there was no evidence of Actidione injury to the developing roots and shoots.

The Effect of Interference with the Water Supply of Cuttings Dipped in Acti-dione and Inoculated with Hypoxylon

Disease attack occurred when dipped cuttings were allowed to dry gradually for a period after inoculation (Fig. 2). The drying treatment did not seriously injure the diseased cuttings and when water was supplied to this material canker growth was arrested. The results demonstrated that Actidione was not effective in disease control when interference was made to the normal water relations of the host. Furthermore, blackened areas appeared on the developing roots and shoots which indicated that the antibiotic had been injurious to the new growth on these partially-dried cuttings.

\section{DISCUSSION AND SUMMARY}

It was of importance that the control of Hypoxylon canker by either Acti-dione or extracts of bark saprophytes (3) was dependent on the provision of a continuous water supply to the host trees. Success in these methods of biological control was only possible when no serious interference was made to the water relations of the trees tested.

The Acti-dione dip caused injury to the shoots and roots that developed on cuttings subjected to a period of drought before water was provided. Boyce (4) has reported that Acti-dione sprays were injurious to the terminal shoots of white pine. No injury of this character was observed on the cuttings that had been dipped in extracts of the bark saprophytes (3). Indeed, the results of preliminary experiments have indicated that these extracts may have contained growth substances that promoted the development of branch roots (Figs. 3, 4, 5 and 6). Detailed studies on the rooting behaviour of extract-treated cuttings are in progress and the results will be published at a later date. It was of considerable interest, therefore, that the extracts of bark saprophytes may have served a dual function, namely, provided a method for the biological control of Hypoxylon canker, and supplied the cuttings with growth substances that stimulated rooting which would result in a higher level of tree vigour.

Under field conditions the lowest levels in bark moisture occur during

Figures 1-6 are on page 347 and 348 
the lengthy period of dormancy (1). It has been demonstrated that immediate results in these methods of biological control required normal or above normal levels in bark moisture. It is possible that the degree of success achieved in field trials of these methods of biological control may vary with time of application, and the water relationships of the trees or stands tested.

It is of importance to mention that chemical control methods may not only destroy pathogens but also the useful saprophytes. However, the applications of natural saprophytes and/or their extracts have been shown to supplement the natural resistance of trees to canker attack.

\section{REFERENCES}

1. BIER, J. E. 1959. The relation of bark moisture to the development of canker diseases caused by native, facultative parasites. I. Cryptodiaporthe canker on willow, Can. J. Botany, 37, 781-788.

2. BIER, J. E. 1961. The relation of bark moisture to the development of canker diseases caused by native, facultative parasites. VI. Pathogenicity studies of Hypoxylon pruinatzum (Klotzsch) Cke., and Septoria mussiva Pk. on species of Acer, Populus, and Salix. Can. J. Botany, 39, 1555-1561.

3. BIER, J. E. and MARIAN H. ROWAT. 1962. The relation of bark moisture to the development of canker diseases caused by native, facultative parasites. VII. Some effects of the saprophytes on the bark of poplar and willow on the incidence of Hypoxylon canker. Can. J. Botany, 40, 61-69.

4. BOYCE, J. S. 1961. Forest Pathology, McGraw-Hill Book Company, New York. (3rd Edition). 